\title{
EFFECTS OF MICROSTRUCTURE ON ROOM TEMPERATURE FATIGUE CRACK INITIATION AND SHORT CRACK PROPAGATION IN UDIMET 720Li Ni-BASE SUPERALLOY.
}

\author{
H.T. Pang" and P.A.S. Reed \\ Materials Research Group, School of Engineering Sciences, University of Southampton, \\ Highfield, Southampton SO17 1BJ, United Kingdom.
}

\begin{abstract}
An assessment of the effects of microstructure on room temperature fatigue crack initiation and short crack propagation in a Ni-base superalloy is presented. The assessment was carried out on microstructural variants of U720Li, including as-received U720Li, U720Li-LG (large grain variant) and U720Li-LP (large intragranular coherent $\gamma^{\prime}$ variant). Fatigue tests were carried out at room temperature using a $20 \mathrm{~Hz}$ sinusoidal cycling waveform on plain bend bars. Tests were conducted in 3-point bend under load control with an R-ratio of 0.1. A maximum load of $95 \% \sigma_{\mathrm{y}}$ was used in all tests. Room temperature fatigue crack initiation was noted to occur due to slip band cracking and from porosity on or just beneath the surface in all materials. Crack propagation was noted to be highly faceted (due to planar slip band cracking) immediately after crack initiation followed by a transition to a flatter Stage II type crack path as crack length increases. U720Li-LP was noted to show the longest fatigue lifetime, followed by U720Li-LG while U720Li shows the shortest life. The longer lifetime of U720Li-LP was linked to a higher resistance to both fatigue crack initiation and short crack propagation. U720Li and U720Li-LG show approximately similar crack initiation resistance although U720Li-LG showed slightly improved short crack growth resistance. The observations have been rationalised in terms of the microstructural characteristics of the materials, and it is believed that larger grain size, larger coherent $\gamma^{\prime}$ precipitate size and higher volume fractions of both coherent and primary $\gamma^{\prime}$ precipitates will improve overall fatigue
\end{abstract}

\footnotetext{
"Now at Dept. of Materials Science \& Metallurgy, University of Cambridge, Pembroke Street, Cambridge CB2 3QZ, UK
} 
lifetimes in PM Ni-base alloys which exhibit planar slip characteristics at room temperature.

Keywords: Udimet 720Li, microstructural effects, fatigue crack initiation, short crack growth, planar slip.

\section{INTRODUCTION}

The nickel-base superalloy Udimet 720Li (U720Li) has been developed for turbine disc applications in response to the increasing demand for higher engine operating temperatures to improve aeroengine efficiency. The operating conditions of turbine discs are extremely severe, as they are subjected to repeated start-up and shutdown cycles in addition to prolonged application of load in the presence of corrosive exhaust gases at elevated temperatures during service. Under these conditions, turbine discs experience fatigue, creep, oxidation and corrosion, all of which are likely to synergistically and significantly reduce the usable life of the component. Nickel-base superalloys have conventionally been chosen for turbine disc applications as they possess a good balance of properties to withstand the severe operating conditions experienced by turbine discs.

Nickel-base superalloys for turbine disc applications are polycrystalline, with an austenitic FCC $\gamma$ matrix strengthened mainly by coherent nickel-rich $\gamma^{\prime}$ precipitates. Incoherent primary $\gamma^{\prime}$ precipitates residing mainly at grain boundaries may also be present depending on heat treatment conditions. Such primary $\gamma^{\prime}$ precipitates may for example arise from sub-solvus solution heat treatment of powder metallurgy (PM) superalloys where not all $\gamma^{\prime}$ from the original powder particles was dissolved. The microstructure of nickel-base superalloys can be manipulated by altering heat treatment conditions allowing variation in grain size and the amount and size distributions of primary $\gamma^{\prime}$ and coherent (secondary and tertiary) $\gamma^{\prime}$ precipitates. This in turn gives rise to a variety of mechanical properties, which may be optimised to give improved overall component life.

Fatigue crack initiation and short crack growth are important as a majority of turbine disc fatigue life is spent in this fatigue regime during service $[1,2,3,4]$. This is because high component stresses result in a relatively small extent of fatigue crack 
propagation prior to fast fracture, limiting the fatigue life to the short crack growth regime $[5,6]$. The influence of microstructure and environment on fatigue crack initiation and short crack growth has been shown to play a dominant role, especially on cracks which are of a size comparable to the scale of characteristic microstructural features $[2,7]$.

At room temperature, fatigue cracks have been found to initiate from slip bands $[8,9,10,11]$, twin boundaries [10], grain boundaries [12], at carbides [13], due to cracking of inclusions/precipitates [2], or at other features from materials processing, such as pores [14]. The small fatigue cracks that are formed immediately after initiation tend to exhibit anomalously high, irregular growth rates when compared to large cracks at similar $\Delta K$ $[2,15,16]$. These small cracks could also grow below the threshold $\Delta K$ found for large cracks $[17,18,19]$. These discrepancies are due to the inability of the stress intensity factor $K$ to correctly describe the magnitude of the crack tip stress-strain field for the case of short cracks [15], where the driving force for short crack growth is noted to be significantly higher than that described by $K$ and LEFM predictions. As such, conventional methods of life prediction, e.g. using integration of the $d a / d N$ vs. $\Delta K$ relationship determined from long crack data, between an initial flaw size and a critical flaw size may lead to non-conservative estimates of component life if short crack propagation characteristics are not taken into account [15].

A study has therefore been carried out to investigate the effects of grain size and $\gamma^{\prime}$ size/distribution variation on fatigue crack initiation as well as short crack and long crack growth in powder metallurgy (PM) nickel-base superalloy U720 Li at both room temperature and $650^{\circ} \mathrm{C}$. This paper in particular concentrates on room temperature initiation and short crack growth behaviour while a recent complementary paper [20] focussed on elevated temperature initiation and short crack growth behaviour and a further paper concentrates on long crack propagation behaviour at room temperature [21]. This paper presents an extension and further discussion of some previously published results [22], and a brief recap of these prior results is also presented. 


\section{MATERIAL}

The materials used in this study were PM turbine disc materials based on Udimet 720Li (U720Li): an as-received version U720Li, a large grain variant U720Li-LG and a large intragranular coherent $\gamma^{\prime}$ precipitate variant U720Li-LP. The composition of U720Li is given in Table 1 and the heat treatment routes used for each material are listed in Table 2. Microstructural variants of U720Li were produced by increasing the solution temperature (to increase grain size) and by slowing the cooling rate from the solution temperature (to increase coherent $\gamma^{\prime}$ precipitate size) [23].

Electrolytic etching with $10 \%$ orthophosphoric acid $\left(\mathrm{H}_{3} \mathrm{PO}_{4}\right)$ in water revealed the microstructure of the test materials as shown in Figure 1. Incoherent primary $\gamma^{\prime}$ precipitates (white) can be distinguished from the $\gamma$ matrix. Grain size and primary $\gamma^{\prime}$ size and volume fraction were determined using image analysis, where an automatic image analysis software Carl Zeiss KS300 (by Carl Zeiss Vision) was used to quantify various parameters (e.g. equivalent circular diameter, ferets, area) of the grains and primary $\gamma^{\prime}$ precipitates. Coherent $\gamma^{\prime}$ characterisation was carried out by analysing carbon extraction replicas on a JEOL 2000FX TEM operating at 200kV. Subsequent image analysis of TEM images yielded the size characteristics of coherent secondary and tertiary $\gamma^{\prime}$ precipitates. The microstructural characteristics of the materials as well as the hardness of the materials at room temperature are presented in Table 3. It can be seen that the alloys have the following hardness (and hence estimated strength) ranking at room temperature: U720Li > U720Li-LG > U720Li-LP.

\section{EXPERIMENTAL}

Short crack tests were carried out at room temperature on an Instron $8802( \pm 10 \mathrm{kN}$ capacity) and an Instron $8502( \pm 100 \mathrm{kN}$ capacity) servohydraulic testing machine. All tests were conducted in 3-point bend under load control using an R-ratio of 0.1 and a $20 \mathrm{~Hz}$ sinusoidal cycling waveform. A span of $30 \mathrm{~mm}$ and maximum stress level of $95 \%$ of estimated $\sigma_{\mathrm{y}}$ (based on hardness tests) were used in all tests (so all materials were compared at equivalent strain levels). Tests were carried out on plain bend bar specimens where the top surface was ground and polished to 1 micron finish. Some of the plain bend bar specimens were also etched with Fry's reagent $(500 \mathrm{ml}$ of concentrated $\mathrm{HCl}$ and $100 \mathrm{~g}$ 
of $\mathrm{CuCl}$ mixed in $500 \mathrm{ml}$ of $\mathrm{H}_{2} \mathrm{O}$ ) prior to testing. Tests on etched specimens reveal the crack path relative to grain boundaries and primary $\gamma^{\prime}$ precipitates, whereas as-polished specimens enable easier detection of initiation events and also serve to check whether etching has any effect on crack initiation, propagation and fatigue lifetimes. Crack initiation and short crack growth were monitored using an acetate replication technique where the tests were interrupted and a replica of the top surface was taken at every 10000 cycles until a crack is first observed, and then at every 5000 cycles until failure. Initiation points were identified and crack growth rates of surface cracks were calculated from the replica record. Short crack growth rates were plotted against crack length as well as against $\Delta K$. Stress intensity factor $K$ values were calculated from the half surface crack length using the empirical formula of Scott and Thorpe [24]. All $K$ calculations assumed a crack depth to half surface crack length ratio $(a / c)$ of 1 . The validity of this assumption is discussed further in the Results section. Detailed fractographic work to examine the fracture surfaces was carried out in a JEOL JSM-T300 SEM operating at an accelerating voltage of $20 \mathrm{kV}$.

\section{RESULTS}

\section{Overall fatigue behaviour}

A summary of the short crack test results is given in Table 4. Overall more cracks were observed in as-polished specimens compared to etched specimens, although this may be due to cracks being obscured on the etched specimens. As-polished specimens also appear to possess a slightly shorter lifetime compared to etched specimens, indicating that etching has offered a slight improvement to fatigue life. U720 Li and U720Li-LG are generally observed to have more cracks compared to U720Li-LP. In terms of lifetimes, U720Li-LP shows the longest fatigue life, followed by U720Li-LG while U720Li exhibits the shortest fatigue life.

\section{Fatigue crack initiation}

During analysis of the acetate replica records, fatigue crack initiation was divided into two distinct types: i) due to porosity or defects on the surface where during examination of the replicas the crack was observed to emanate from a pore or a defect on 
the surface, and ii) due to slip band cracking or subsurface defects where the crack was noted to appear on the surface without any evidence of surface pore or defect causing the crack initiation. A summary of the fatigue crack initiation information is given in Table 4. Crack initiation appears to be largely dominated by porosity in U720Li and U720Li-LG, while in U720Li-LP there is a balance between the number of cracks due to porosity and those due to slip band cracking/subsurface defects. Based on the limited evidence obtained in this study, cracks were generally noted to initiate much earlier in U720Li and U720Li-LG compared to U720Li-LP (Table 4), which may suggest a less damage tolerant and/or lower crack initiation-resistant microstructure of U720Li and U720Li-LG. U720Li-LP also appears to have increased resistance to crack initiation in the presence of porosity. SEM observations at and near the crack initiation site of primary cracks are shown in Fig. 2. The primary crack and larger secondary cracks in all tests were noted to initiate from porosity on or just below the surface, which reinforces the observation of crack initiation due to porosity on the surface during replica examination. The crackinitiating porosity may be clustered (Fig. 2b) or have elongated shapes (Fig. 2c).

\section{Short crack propagation}

Short crack growth rates vs. $\Delta K$ plots for each material are shown in Fig. 3a to Fig. 3c. Only larger cracks (i.e. the primary crack and secondary cracks $>50 \mu \mathrm{m}$ at failure) were analysed as most of the smaller cracks ( $<50 \mu \mathrm{m}$ at failure) in the tests showed small/negligible crack growth rates or were arrested throughout the tests. The

plots show scatter typical of short crack growth at low $\Delta K$, where temporary crack arrests due to obstacles (primary $\gamma^{\prime}$ precipitates, grain boundaries) are common. At higher $\Delta K$ levels the crack growth data seems to converge to a more consistent (long crack growth) curve. From these plots, it can be seen that etching has not significantly affected the short crack growth rates, whilst giving the benefit of revealing the crack path relative to the microstructure.

When calculating the $\Delta K$ values using the empirical formula of Scott and Thorpe [24], it was assumed that the crack depth is equivalent to half the surface crack length, i.e. an $a / c$ ratio of 1 . This assumption was made for simplicity, but the crack shape may invalidate this assumption at larger crack lengths. Care also has to be exercised when 
using the $\Delta K$ parameter, especially when comparing the results of this study with others due to the number of cracks on each specimen and the proximity of the cracks to one another. Nevertheless, in the absence of a better alternative, the $\Delta K$ parameter serves as a reasonable correlating parameter within this study to compare the crack growth behaviour of the microstructural variants.

Fig. 4 gives a comparison of short crack growth rates for the materials tested in the study. In the short crack growth regime ( $\Delta K$ approximately $<10 \mathrm{MPa} \sqrt{\mathrm{m}}$, corresponding to crack lengths $\sim 200 \mu \mathrm{m}$ ), U720Li-LP appears to exhibit approximately similar or lower crack growth rates compared to U720Li-LG, while U720Li shows the highest average short crack growth rates among all the materials tested in the study. U720Li and U720Li-LG show larger scatter in crack growth rates, possibly due to the higher number of cracks in both the U720Li and U720Li-LG tests. Another useful method to quantify short crack growth resistance of the materials is by comparing the fastest growing crack, usually the largest (primary) crack in the specimen (i.e. the one which is most critical to failure) in each test. Fig. 5 shows that while most of the cracks critical to failure initiate after approximately the same number of cycles, the crack growth is distinctly different. Crack growth of the largest crack in U720Li-LP is slowest, followed by U720Li-LG and U720Li.

Crack growth around the crack initiation site appears faceted, indicative of Stage I crack growth. The fracture surfaces become less faceted as the crack grows, indicating the onset of Stage II crack growth mode. Fig. 6 shows the transition from Stage I to mixed Stage I/Stage II crack in all 3 alloys (the crack is growing from the top to bottom in each figure). Some degree of crystallographic faceted crack growth is observed at the top of each figure, with relatively flat regions indicative of Stage II crack growth noted nearer to the bottom. The transition from Stage I to Stage II crack growth was gradual, usually over a few tens of $\mu \mathrm{m}$. The crack length, $c_{\text {trans }}$, at which the observed transition from Stage I to Stage II occurs on the fracture surface were estimated in each material and are shown in Table 5. These data are used later for comparison of room temperature short crack and long crack growth behaviour [21].

A comparison of the crystallographic crack growth nature near the primary crack initiation site in Fig. 6 indicates highly crystallographic facets in U720Li-LG, slightly 
less so in U720Li while for U720Li-LP crack growth immediately after crack initiation appeared the least crystallographic. This observation may indicate the degree of slip planarity experienced in each material when tested under similar fatigue conditions.

The acetate replica records also revealed multiple temporary crack arrest events when a crack approached a primary $\gamma^{\prime}$ precipitate in all the short crack tests. The crack continues either by cutting through or propagating around the primary $\gamma^{\prime}$ precipitates. Fig. 7 gives an example of temporary crack arrest which involves the crack cutting through a primary $\gamma^{\prime}$ precipitate in U720Li. Note the initiation of the fatigue crack from porosity.

An assessment of the effects of primary $\gamma^{\prime}$ precipitates on the propagating crack tip on the top surface of the short crack specimens was carried out by observation of the acetate replicas. The assessment was carried out only on etched tests (where primary $\gamma^{\prime}$ precipitates were revealed) and on larger cracks $(>50 \mu \mathrm{m})$. The number of primary $\gamma^{\prime}$ precipitates encountered by the crack, either through cutting of the precipitate or propagation around the precipitate (bowing) was recorded for individual cracks at $40 \mu \mathrm{m}$ intervals. The results of the assessment are presented as the averaged behaviour for each material, with the number and type of primary $\gamma^{\prime}$ precipitate-crack interactions shown in Fig. $8 \mathrm{a}$ to Fig $8 \mathrm{c}$. It was noted that cutting or bowing of the primary $\gamma^{\prime}$ precipitates by the advancing crack was equally common in all the materials and the number of cycles of crack arrest for each primary $\gamma^{\prime}$ precipitate-crack interaction appears to be similar. A comparison of the overall number of crack tip interactions with primary $\gamma^{\prime}$ precipitates during crack propagation in the test materials is shown in Fig. 9. On average, the number

of primary $\gamma^{\prime}$ precipitates encountered by the cracks was highest in U720Li-LP, followed by U720Li while the cracks in U720Li-LG encountered the lowest number of primary $\gamma^{\prime}$ precipitates.

\section{DISCUSSION}

\section{Factors controlling room temperature fatigue crack initiation}

Crack initiation occurred due to intrinsic factors such as slip band cracking or due to defects and pores. Slip band crack initiation occurs due to the planar slip character of nickel-base superalloys at low temperatures. Intense impingement of slip bands occurs at grain boundaries due to build-up of dislocation density in the slip bands. Weakening of 
the slip band occurs due to repeated load cycling causing dislocations to move back and forth in the slip bands, and eventually the slip band material is weakened to the point where it is fractured (shear decohesion) and initiates a crack. The presence of defects and pores in the material can also cause crack initiation as the defects and pores may act as stress concentrators or discontinuities on the surface or within the material, favouring nucleation of fatigue cracks in these regions of locally raised stresses.

Goto and Knowles [2] investigated the initiation and propagation of microcracks in $\mathrm{U} 720 \mathrm{Li}$ at room temperature and found that at extremely early stages of cycling, cracking of TiN particles occurred. The cracked particles were then responsible for the initiation of subsequent fatigue cracks. There is little evidence that TiN particles are present in the materials used in the current study. The microstructure of the U720Li material used by Goto and Knowles contained TiN particles having sizes similar to or larger than the primary $\gamma^{\prime}$ precipitates. It is possible that the large TiN particles in their study therefore cracked easily contributing to the initiation of fatigue cracks.

\section{Factors controlling Stage I and Stage II crack growth behaviour}

Immediately after crack initiation, Stage I type crack growth was observed in all alloys at short crack lengths. Stage I crack growth corresponds to crack growth where the zone of plastic deformation surrounding the crack tip is confined to within a few grains, and crack growth occurs predominantly along slip bands in the slip system experiencing the maximum resolved shear. This gives rise to a zig-zag crack path and a highly facetted fracture surface as the crack path changes with slip systems going from grain to grain, as observed during early short crack growth. The plastic zone size associated with the small crack length immediately after crack initiation is much smaller than the grain size, and crack propagation occurs along the slip system experiencing maximum shear within the grain. Stage I crack growth is generally considered to be highly sensitive to the local microstructure e.g. grain boundaries. Other extrinsic factors (e.g. crack closure, crack tip shielding, etc) which can affect crack growth may be enhanced due to this deflected crack growth mode. At longer crack lengths, the plastically deformed zone ahead of the crack tip increases to encompass several grains, and slip systems in several grains are activated. At this point, crack growth is able to occur through simultaneous or co-operative slip 
along these multiple slip systems, i.e. Stage II crack growth. Stage II crack growth is characterised by a relatively flat and featureless fracture surface. Stage II crack growth is less sensitive to local microstructure compared to Stage I crack growth and the crack samples the averaged microstructural characteristics of the material.

Transition crack lengths (from Stage I to Stage II type cracking, denoted $c_{\text {trans }}$ ) were measured from short crack fractography and are shown in Table 5. The $\Delta K$ corresponding to these transitional crack lengths were found using the empirical formula of Scott and Thorpe [24] and the corresponding plastic zone sizes are calculated using Irwin's approximation [25]. As previously mentioned, Stage I crack growth is thought to occur when crack tip plasticity is totally contained within the grains, i.e. when the monotonic plastic zone size is less than the grain size. As the crack length increases, so does the associated plastic zone, which may then exceed smaller grains at the crack tip, due to the inherent grain size distribution. When this happens, the crack front grows in a Stage II manner in these smaller grains, whilst Stage I crack growth is promoted in those larger grains which could still contain the crack tip monotonic plastic zone. For fully Stage II crack growth, the definitive onset of this stage may be considered to occur when the cyclic plastic zone size exceeds the grain size, between these two stages a mixed Stage I/Stage II crack growth mode will be observed.

Based on these analyses of expected plastic zone sizes for the end of Stage I, mixed Stage I/Stage II and fully Stage II growth, the short crack fractography measurements revealed the end of pure Stage I crack growth, but did not pick up the commencement of fully Stage II crack growth. This is indicated by the generally larger monotonic plastic zone size but much smaller cyclic plastic zone size in comparison to the average grain size of the materials in Table 5. Corresponding room temperature long crack tests have been carried out on these materials to complement the current short crack test results, and are fully discussed elsewhere [21]. Comparison of the short crack and long crack test data has enabled the $\Delta K$ at which the short crack and long crack growth rates converge $\left(\Delta K_{\text {conv }}\right)$ to be determined as shown in Table 6 . Convergence of the short crack and long crack growth curves is another indication of the transition to structureinsensitive crack growth, i.e. Stage II crack growth. Based on this $\Delta K_{\text {conv }}$, the short crack length at which fully Stage II crack growth occurs is estimated, as well as the associated 
monotonic and cyclic plastic zone size corresponding to $\Delta K_{\text {conv }}$ in Table 6 . The point of convergence of the long crack and short crack growth rates correlates better with the expected onset of fully Stage II crack growth i.e. when the crack tip cyclic plastic zone size exceeds the average grain size. When this happens, every point along the crack front of the short crack and long crack are similar, i.e. both are growing in a pure Stage II crack growth mode. The short crack fractography has not picked up the onset of fully Stage II crack growth as it is difficult to distinguish mixed Stage I/Stage II crack growth from fully Stage II crack growth.

Table 5 shows the crack length, $c_{\text {trans }}$, at the end of pure Stage I crack growth and Table 6 shows the crack length, $c_{c o n v}$, corresponding to the onset of fully Stage II crack growth. Based upon crack length $a$ versus $N$ data from the replica record, the proportion of life spent in the different regimes of crack growth, i.e. pure Stage I, mixed Stage I/Stage II and pure Stage II can therefore be estimated for the materials as shown in Table 7. The number of cycles for each stage is estimated to the closest 5000 or 10000 cycles due to the replication frequency adopted. The results shown in Table 7 indicate that approximately $70 \%$ of the total life demonstrated in the room temperature short crack tests is spent in the crack initiation and pure Stage I crack growth regimes in all the materials. Mixed Stage I/Stage II crack growth mode accounts for another 15\% of the life after the end of pure Stage I crack growth. The onset of pure Stage II crack growth at approximately $85 \%$ of the life takes up the remainder of the fatigue life in the materials. Hence the fatigue lives of the materials in these room temperature short crack tests are dominated by crack initiation and early crack growth in the Stage I crack growth mode.

\section{Microstructure effects on room temperature fatigue crack initiation}

The microstructure effects on room temperature fatigue crack initiation and short crack growth are principally governed by planarity of slip in the materials. Crack initiation from slip band cracking and crack growth under Stage I crack growth (which predominates in these tests) is heavily dependent on slip character. Crack initiation from porosity is also likely to be influenced by slip character as crack initiation from porosity is likely to occur along intense slip bands close to the pore aided by the stress concentration of the pore. 
Fig. 2 and Fig. 6 show that immediately after crack initiation, highly crystallographic facets were noted in U720Li-LG with smaller facets observed on the U720Li fracture surface while crack growth immediately after crack initiation on the fracture surface of U720Li-LP was least crystallographic. Higher crack initiation resistance is expected for the material showing the lowest degree of slip planarity. Less planar slip has been associated with strain accommodation within the slip band, thus reducing dislocation pile-up length within the slip band for slip band cracking [26] and also resulting in the material being more damage tolerant to cyclic deformation in the presence of stress concentrators such as pores. The highest crack initiation resistance may therefore be expected in U720Li-LP, followed by slightly lower crack initiation resistance in U720Li while U720Li-LG is expected to show the lowest crack initiation resistance. This trend of crack initiation resistance was indeed observed when comparing the number of cracks in the materials. Fewer cracks were noted in the U720Li-LP tests compared to other materials. U720Li and U720Li-LG show relatively similar numbers of cracks in the tests, which may be related to the similar planar slip mechanism in these materials. U720Li-LP also shows better resistance to crack initiation due to surface porosity compared to other materials which is likely to be linked to the more homogeneous slip behaviour of this material. In U720Li and U720Li-LG, the first observed crack from surface porosity was noted generally after 10000 cycles; crack initiation is likely to be accelerated by the planar slip behaviour in these materials.

\section{Microstructure effects on room temperature short crack growth}

A combination of dislocation-precipitate cutting and bowing mechanisms is likely to be prevalent in U720Li-LP due to the large coherent tertiary $\gamma^{\prime}$ precipitate size in the material, whereas the finer tertiary $\gamma^{\prime}$ precipitate sizes in U720Li and U720Li-LG are likely to promote mainly dislocation-precipitate cutting. Precipitate bowing mechanisms are likely to promote less planar slip whilst precipitate cutting gives rise to more reversible or planar slip. Planarity of slip has various opposing effects on short crack growth resistance. Firstly, highly planar slip has been associated with more intense impingement of slip bands at grain boundaries due to greater pile-up of dislocations in the slip bands. Therefore dislocation sources are able to nucleate more easily in the adjacent 
grain and crack growth processes continue in the next grain. Under such circumstances, grain boundaries are less effective as crack growth barriers, resulting in poorer crack growth resistance. Secondly, planar slip has also been associated with increased reversibility of slip giving lower damage accumulation and increased intrinsic crack growth resistance. Finally, highly planar slip has also been associated with more tortuous crack paths compared to homogeneous slip. Large crack path deflection with heterogeneous slip due to intense slip bands extending across the grain may give rise to increased crack tip shielding.

Further local microstructural effects on short crack growth resistance arise from grains and primary $\gamma^{\prime}$ precipitates. Grain size gives rise to two opposing effects on short crack growth resistance. Firstly, grain size reflects the number of grain boundaries acting as barriers to dislocation motion, which are in turn crack growth barriers. Materials with larger grains have less grain boundaries, giving a lower degree of discontinuity in the material and cracks are able to propagate more continuously resulting in poorer crack growth resistance. Secondly, grain size together with the planar slip behaviour of the material also influences extrinsic crack growth resistance. Larger grains have also been associated with a more tortuous crack path, giving increased crack tip deflection and shielding which will result in better crack growth resistance. The effect of grain size on the crack growth barrier effect and the extrinsic crack growth resistance contributions are therefore two opposing effects on short crack growth resistance for a particular grain size.

Primary $\gamma^{\prime}$ precipitates were noted to give rise to multiple temporary crack arrest events by acting as effective crack growth obstacles. A higher frequency of these precipitates in the material may then be expected to give better crack growth resistance during early short crack growth. In considering the effect of primary $\gamma^{\prime}$ precipitates during early crack growth, the materials in this study all have approximately similar primary $\gamma^{\prime}$ size, hence higher short crack growth resistance may be expected from material with a high volume fraction of primary $\gamma^{\prime}$ precipitates (such as U720Li and U720Li-LP). To summarise these opposing effects of microstructure on short crack fatigue resistance in the microstructural variants, a relative ranking is given to each contributing mechanism and compared with the observed overall ranking in resistance to 
Stage I crack growth, as shown in Table 8 (1 giving the greatest, and 3 giving the least contribution to Stage I crack growth resistance).

The highest Stage I crack growth resistance was noted in U720Li-LP, followed by U720Li-LG while U720Li showed the lowest Stage I crack growth resistance. This is also highlighted in Fig. 5 where at crack lengths up to approximately $100 \mu \mathrm{m}$, crack growth of the primary crack was noted to be slowest in U720Li-LP, followed by U720LiLG while U720Li shows the most rapid growth of the primary crack. Overall, in U720LiLP, the combination of: (1) precipitate cutting and bowing mechanisms leading to reduced impingement of slip bands at grain boundaries (2) some degree of reversible slip (3) the crack growth barrier effects of grain boundaries and (4) primary $\gamma^{\prime}$ precipitates giving temporary crack arrests offsets the lower degree of slip reversibility and possible crack tip shielding, giving the highest Stage I crack growth resistance in the room temperature short crack tests. Comparing U720Li and U720Li-LG, poorer crack growth barrier effects and the lower number of primary $\gamma^{\prime}$ precipitates encountered in U720LiLG $c f$. U720Li suggests lower crack growth resistance in U720Li-LG but this is overcome by the increase in crack growth resistance associated with increased reversibility of slip and the possible increase in crack tip shielding due to larger grain sizes in U720Li-LG. Intense impingement of slip bands at grain boundaries are expected to be relatively similar in both U720Li and U720Li-LG but much higher $c f$. U720Li-LP due to dislocation pile-ups associated with planar slip behaviour in both U720Li and U720Li-LG.

Crack tip shielding and reversibility of slip appear to make a greater contribution to crack growth resistance during Stage I early crack growth compared to the crack growth barrier effects of local microstructure. In U720Li-LG, higher crack growth resistance contributions from crack tip shielding and slip reversibility are able to overcome the decrease in crack growth resistance due to poorer crack growth barrier effects associated with larger grains and lower number of primary $\gamma^{\prime}$ precipitates encountered by the crack giving significant improvement in crack growth resistance in U720Li-LG compared to U720Li. 


\section{Optimised microstructures for room temperature fatigue crack initiation and short crack growth resistance}

At room temperature, early initiation has been observed where porosity has been noted to initiate the fatal crack in all cases, indicating the importance of porosity control for these PM materials. A higher amount of porosity on the surface of the material is therefore expected to be detrimental to crack initiation resistance by providing more sites for crack initiation.

Independent control of microstructural variables during fabrication of these microstructural variants was difficult. Heat treatment routes which increased grain size would reduce the amount of primary $\gamma^{\prime}$ whilst increasing the amount of coherent $\gamma^{\prime}$ (e.g. compare U720Li and U720Li-LG). This complex interaction of microstructural features makes characterising short crack growth resistance contribution due to a particular change in microstructural feature difficult. U720Li-LP also represents a relatively rare case where the tertiary $\gamma^{\prime}$ precipitates are sufficiently large to produce dislocationprecipitate bowing mechanisms. In commercial turbine disc alloys, the tertiary $\gamma^{\prime}$ precipitates are relatively fine such that precipitate cutting mechanisms predominantly operate. Microstructures demonstrating lower slip planarity have been shown to give improved crack initiation resistance for slip band cracking and cracks initiating from porosity. As such, materials with combinations of finer grain and finer coherent $\gamma^{\prime}$ precipitates are expected to show improved fatigue crack initiation resistance, as is the case when comparing U720Li and U720Li-LG where U720Li showed slightly better fatigue crack initiation resistance. U720Li-LP shows high fatigue crack initiation resistance with its large coherent $\gamma^{\prime}$ precipitate size due to dislocation-precipitate bowing mechanisms in this material giving homogeneous slip.

In terms of short crack growth, materials with larger grain size, and larger coherent $\gamma^{\prime}$ size (below the dislocation-precipitate cutting to bowing transition) and a higher amount of coherent $\gamma^{\prime}$ precipitates giving rise to more planar slip [27] are expected to give higher short crack growth resistance, as seen when comparing U720Li and U720Li-LG. For U720Li-LP, where dislocation-precipitate cutting and bowing is prevalent, reduced slip band impingement at grain boundaries associated with large coherent $\gamma^{\prime}$ precipitates coupled with the increased crack growth barrier effect of grain 
boundaries associated with the finer grains is able to offset the lack of crack tip shielding and reversibility of slip to still give the highest short crack growth resistance. The optimal grain size for short crack growth resistance therefore appears to be dependent on the planarity of slip in the materials, where for materials which undergo planar slip, larger grains are better while for materials which undergo more homogeneous slip (e.g. dislocation-precipitate cutting and bowing), finer grains give better short crack growth resistance.

Materials with more discrete primary $\gamma^{\prime}$ precipitates providing crack growth barrier effects are expected to demonstrate improved short crack growth resistance. For a given primary $\gamma^{\prime}$ precipitate size, materials with a higher volume fraction of primary $\gamma^{\prime}$ precipitates are expected to show better short crack growth resistance.

From our results, in PM Ni-base alloys which undergo planar slip, improved room temperature fatigue crack initiation resistance is noted with finer grain and finer coherent $\gamma^{\prime}$ precipitate microstructures while improved room temperature short crack growth resistance is shown by materials with larger grain sizes, larger secondary and tertiary $\gamma^{\prime}$ precipitates, a greater proportion of coherent $\gamma^{\prime}$ precipitates and a higher volume fraction of primary $\gamma^{\prime}$ precipitates. Generally speaking, however, an increase in grain size in PM superalloys can only be achieved by a decrease in volume fraction of primary $\gamma^{\prime}$. As crack initiation was noted to occur quite early in life, the factors which govern short crack growth resistance are likely to govern overall fatigue lifetimes in the room temperature short crack tests in this study.

\section{SUMMARY AND CONCLUSIONS}

Room temperature short crack tests have been carried out on U720Li and microstructural variants of U720Li, i.e. U720Li-LG and U720Li-LP. Fatigue crack initiation was noted to occur due to slip band cracking and from porosity on or just beneath the surface in all materials. Immediately after crack initiation, crack propagation was noted to follow a highly crystallographic crack path. As crack length increases, a transition to a flatter crack path was noted. U720Li-LP shows the longest fatigue lifetime, followed by U720Li-LG and U720Li. U720Li-LP also exhibits better fatigue crack initiation and short crack growth resistance compared to U720Li and U720Li-LG which 
reflects the longer fatigue lifetimes of U720Li-LP. Grain size, volume fraction of primary $\gamma^{\prime}$ and amount and size of coherent $\gamma^{\prime}$ are important factors in determining short crack growth resistance at room temperature. The results of this study indicate that larger grain sizes, larger secondary and tertiary $\gamma^{\prime}$ precipitates, a higher amount of coherent $\gamma^{\prime}$ precipitates and higher volume fraction of primary $\gamma^{\prime}$ precipitates will improve overall fatigue lifetimes in PM Ni-base alloys which undergo planar slip at room temperature.

\section{ACKNOWLEDGEMENTS}

Support from QinetiQ Farnborough, the University of Southampton and the Overseas Research Scholarship (ORS) administered by the Committee of ViceChancellors and Principals, United Kingdom are gratefully acknowledged. 
Tables

\begin{tabular}{|lllllllllll|}
\hline Element & $\mathrm{Cr}$ & $\mathrm{Co}$ & $\mathrm{Ti}$ & $\mathrm{Mo}$ & $\mathrm{Al}$ & $\mathrm{W}$ & $\mathrm{Zr}$ & $\mathrm{B}$ & $\mathrm{C}$ & $\mathrm{Ni}$ \\
\hline $\mathrm{Wt} \%$ & 16 & 15 & 5 & 3 & 2.5 & 1.25 & 0.035 & 0.015 & 0.015 & bal. \\
\hline
\end{tabular}

Table 1: Composition (wt $\%$, balance nickel) of U720Li.

\begin{tabular}{|l|l|l|}
\hline Heat Treatment & Solution treatment & Cooling \\
\hline U720Li & $4 \mathrm{hr} @ 1105^{\circ} \mathrm{C}$ & Oil quench \\
\hline U720Li-LG & $4 \mathrm{hr} @ 1135^{\circ} \mathrm{C}$ & Air cool \\
\hline U720Li-LP & $4 \mathrm{hr} @ 1105^{\circ} \mathrm{C}$ & Insulated air cool \\
\hline
\end{tabular}

Table 2: Heat treatment conditions of test materials. All materials were subsequently subjected to a two-stage ageing heat treatment of $24 \mathrm{hr}$ at $650^{\circ} \mathrm{C}$ followed by $16 \mathrm{hr}$ at $760^{\circ} \mathrm{C}$.

\begin{tabular}{|l|c|c|c|}
\hline Material & U720Li & U720Li-LG & U720Li-LP \\
\hline Average grain size $(\mu \mathrm{m})$ & 6.4 & 15.4 & 10.1 \\
\hline Grain size range $(\mu \mathrm{m})$ & $2-13$ & $5-41$ & $2-21$ \\
\hline Average primary $\gamma^{\prime}$ size $(\mu \mathrm{m})$ & 2.0 & 2.5 & 2.1 \\
\hline Primary $\gamma^{\prime}$ size range $(\mu \mathrm{m})$ & $0.5-6.9$ & $0.9-7.6$ & $0.7-6.5$ \\
\hline Primary $\gamma^{\prime} \mathrm{V}_{\mathrm{f}}(\%)$ & 19 & 9 & 18 \\
\hline $\begin{array}{l}\text { Average secondary } \gamma^{\prime} \text { size } \\
(\text { nm) }\end{array}$ & 102 & 190 & 254 \\
\hline Average tertiary $\gamma^{\prime}$ size $(\mathrm{nm})$ & 16 & 17 & 27 \\
\hline Coherent $\gamma^{\prime}$ amount $(\%)$ & 29 & 40 & 30 \\
\hline Hardness $($ Hv30) & 458 & 445 & 427 \\
\hline
\end{tabular}

Table 3: Microstructural characteristics of test materials. 


\begin{tabular}{|c|c|c|c|c|c|c|c|}
\hline \multirow[t]{2}{*}{ Material } & \multirow[t]{2}{*}{$\begin{array}{l}\text { Specimen } \\
\text { treatment }\end{array}$} & \multirow[t]{2}{*}{$\begin{array}{l}\text { Lifetime } \\
\text { (cycles) }\end{array}$} & \multicolumn{3}{|c|}{ Number of cracks } & \multicolumn{2}{|c|}{$\begin{array}{l}\text { Number of cycles } \\
\text { to first observed } \\
\text { crack }\end{array}$} \\
\hline & & & $\begin{array}{l}\text { Pores/ } \\
\text { features }\end{array}$ & $\begin{array}{l}\text { Slip } \\
\text { band }\end{array}$ & Total & $\begin{array}{l}\text { Pores/ } \\
\text { features }\end{array}$ & $\begin{array}{l}\text { Slip } \\
\text { band }\end{array}$ \\
\hline U720Li & As-polished & 105467 & 20 & 15 & 35 & 10000 & 10000 \\
\hline U720Li & Etched & 128476 & 13 & 2 & 15 & 10000 & 40000 \\
\hline U720Li-LG & As-polished & 170486 & 35 & 6 & 41 & 10000 & 10000 \\
\hline U720Li-LG & Etched & 175867 & 15 & 4 & 19 & 20000 & 10000 \\
\hline U720Li-LP & As-polished & 217861 & 5 & 5 & 10 & 80000 & 10000 \\
\hline U720Li-LP & Etched & 248570 & 5 & 3 & 8 & 70000 & 50000 \\
\hline
\end{tabular}

Table 4: Fatigue crack initiation information, all specimens were tested at $95 \%$ estimated $\sigma_{\mathrm{y}}$

\begin{tabular}{|c|c|c|c|c|c|}
\hline \multirow[t]{2}{*}{ Material } & \multirow{2}{*}{$\begin{array}{l}\text { Approximate } \\
\text { transition } \\
\text { crack length, } \\
c_{\text {trans }}(\mu \mathrm{m})\end{array}$} & \multirow{2}{*}{$\begin{array}{l}\text { Approximate } \\
\Delta \mathrm{K} \text { at } \mathrm{c}_{\text {trans }}, \\
\Delta \mathrm{K}_{\text {trans }} \\
(\mathrm{MPa} \sqrt{\mathrm{m}})\end{array}$} & \multicolumn{2}{|c|}{$\begin{array}{l}\text { Corresponding plastic } \\
\text { zone size at } \Delta \mathrm{K}_{\text {trans }} \\
(\mu \mathrm{m})\end{array}$} & \multirow[t]{2}{*}{$\begin{array}{l}\text { Average } \\
\text { grain size } \\
(\mu \mathrm{m})\end{array}$} \\
\hline & & & Monotonic & Cyclic & \\
\hline U720Li & 110 & 14.7 & 19.1 & 3.9 & 6.4 \\
\hline U720Li-LG & 100 & 12.8 & 15.4 & 3.1 & 15.4 \\
\hline U720Li-LP & 90 & 12.6 & 16.7 & 3.3 & 10.1 \\
\hline
\end{tabular}

Table 5: Approximate stage I to stage II transition crack lengths and associated $\Delta \mathrm{K}$ and plastic zone sizes from fractography observations. 


\begin{tabular}{|c|c|c|c|c|c|}
\hline \multirow[t]{2}{*}{ Material } & \multirow[t]{2}{*}{$\begin{array}{l}\Delta K \text { at } \\
\text { convergence } \\
\Delta K_{\text {conv }}(\mathrm{MPa} \sqrt{\mathrm{m}})\end{array}$} & \multirow[t]{2}{*}{$\begin{array}{l}\text { Short crack } \\
\text { length } c_{\text {conv }} \text { at } \\
\Delta K_{\text {conv }}(\mu \mathrm{m})\end{array}$} & \multicolumn{2}{|c|}{$\begin{array}{l}\text { Corresponding plastic } \\
\text { zone size at } \Delta K_{\text {conv }} \\
(\mu \mathrm{m})\end{array}$} & \multirow[t]{2}{*}{$\begin{array}{l}\text { Average } \\
\text { grain } \\
\text { size }(\mu \mathrm{m})\end{array}$} \\
\hline & & & Monotonic & Cyclic & \\
\hline U720Li & 25 & 325 & 55.3 & 11.2 & 6.4 \\
\hline U720Li-LG & 22 & 300 & 45.4 & 9.2 & 15.4 \\
\hline U720Li-LP & 20 & 230 & 40.7 & 8.2 & 10.1 \\
\hline
\end{tabular}

Table 6: Approximate $\Delta \mathrm{K}$ at convergence (from da/dN behaviour [21]) and associated plastic zone size calculations.

\begin{tabular}{|l|c|c|c|}
\hline Material & U720Li & U720Li-LG & U720Li-LP \\
\hline Lifetime (cycles) & 128476 & 175867 & 248570 \\
\hline $\begin{array}{l}\text { Crack length at end of pure } \\
\text { stage I growth }(\mu \mathrm{m})\end{array}$ & 110 & 100 & 90 \\
\hline $\begin{array}{l}\text { Number of cycles at end of } \\
\text { pure stage I growth }\end{array}$ & 90000 & 110000 & 195000 \\
\hline $\begin{array}{l}\text { \% life spent up to the end of } \\
\text { pure stage I crack growth }\end{array}$ & 70.0 & 62.5 & 78.4 \\
\hline $\begin{array}{l}\text { Crack length at beginning of } \\
\text { pure stage II growth ( } \mu \text { m) }\end{array}$ & 325 & 300 & 230 \\
\hline $\begin{array}{l}\text { Number of cycles at beginning } \\
\text { of pure stage II growth }\end{array}$ & 110000 & 150000 & 220000 \\
\hline $\begin{array}{l}\text { \% life before onset of pure } \\
\text { stage II crack growth at end of } \\
\text { test }\end{array}$ & 85.6 & 85.3 & 88.5 \\
\hline
\end{tabular}

Table 7: Life spent in different crack growth regimes in room temperature short crack tests. 


\begin{tabular}{|c|c|c|c|}
\hline $\begin{array}{l}\text { Mechanism increasing short crack fatigue } \\
\text { resistance }\end{array}$ & U720Li & U720Li-LP & U720Li-LG \\
\hline $\begin{array}{l}\text { Less planar slip - reduction in grain boundary slip } \\
\text { band impingement }\end{array}$ & 2 & 1 & 3 \\
\hline $\begin{array}{l}\text { More planar slip, more deflected crack path, more } \\
\text { crack tip shielding }\end{array}$ & 2 & 3 & 1 \\
\hline $\begin{array}{l}\text { More planar slip - more reversible slip, less } \\
\text { damage accumulation }\end{array}$ & 2 & 3 & 1 \\
\hline Grain size effect - more barriers to crack growth & 1 & 2 & 3 \\
\hline $\begin{array}{l}\text { Grain size effect (coupled with more planar slip) } \\
\text { more deflected crack path, more crack tip } \\
\text { shielding }\end{array}$ & 3 & 2 & 1 \\
\hline Primary $\gamma^{\prime}$ blocking crack growth & 2 & 1 & 3 \\
\hline Overall ranking observed & 3 & 1 & 2 \\
\hline
\end{tabular}

Table 8: Comparison of crack growth resistance mechanisms 


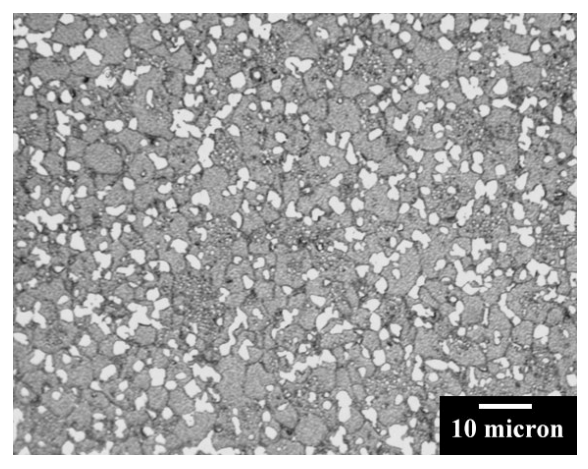

(a)

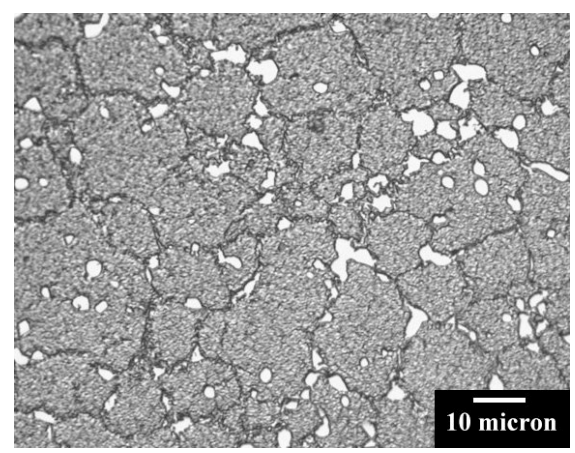

(c)

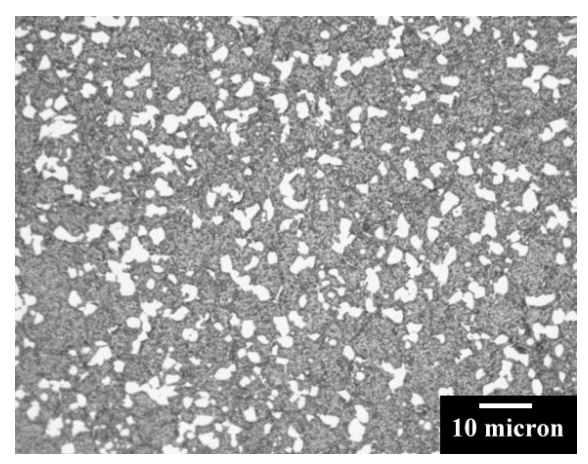

(e)

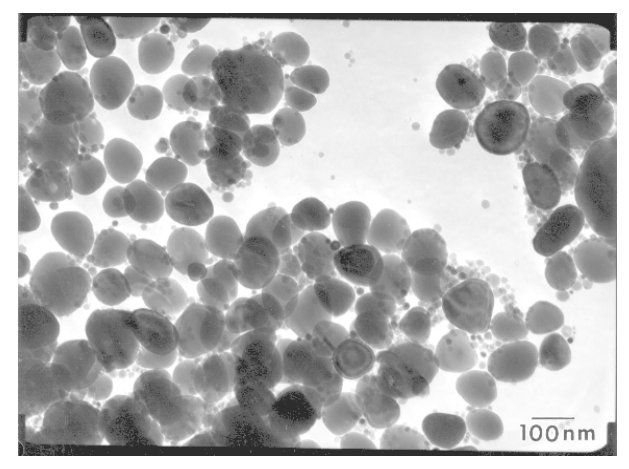

(b)

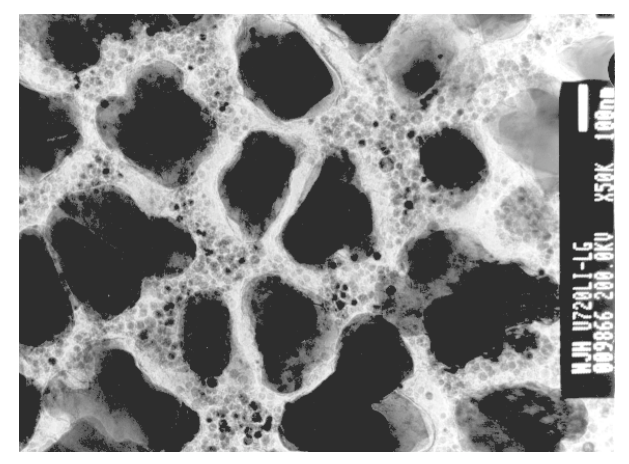

(d)

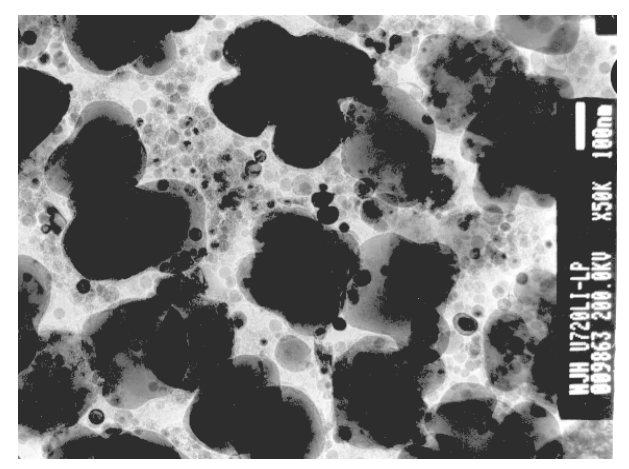

(f)

Figure 1: Microstructure of test materials (a) U720Li - orthophosphoric etch (b) U720Li - carbon extraction replica (c) U720Li-LG - orthophosphoric etch (d) U720Li-LG carbon extraction replica (e) U720Li-LP - orthophosphoric etch (f) U720Li-LP - carbon extraction replica 
(a)

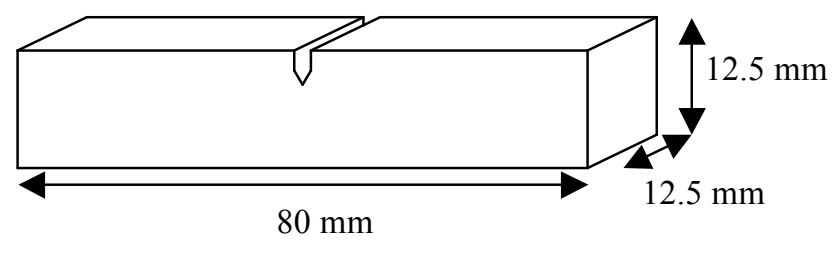

(b)

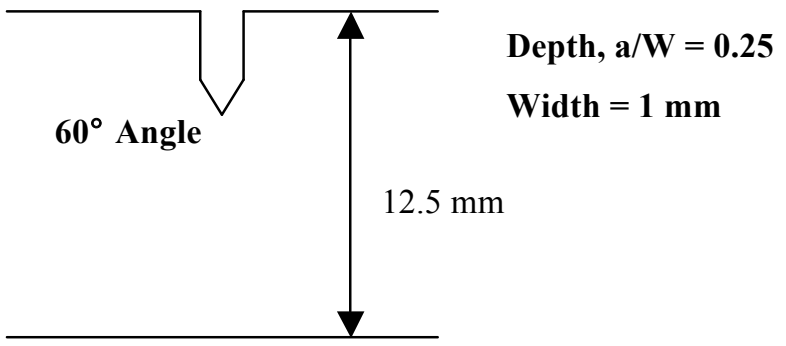

Figure 2: SENB specimen geometry used in long crack tests. 


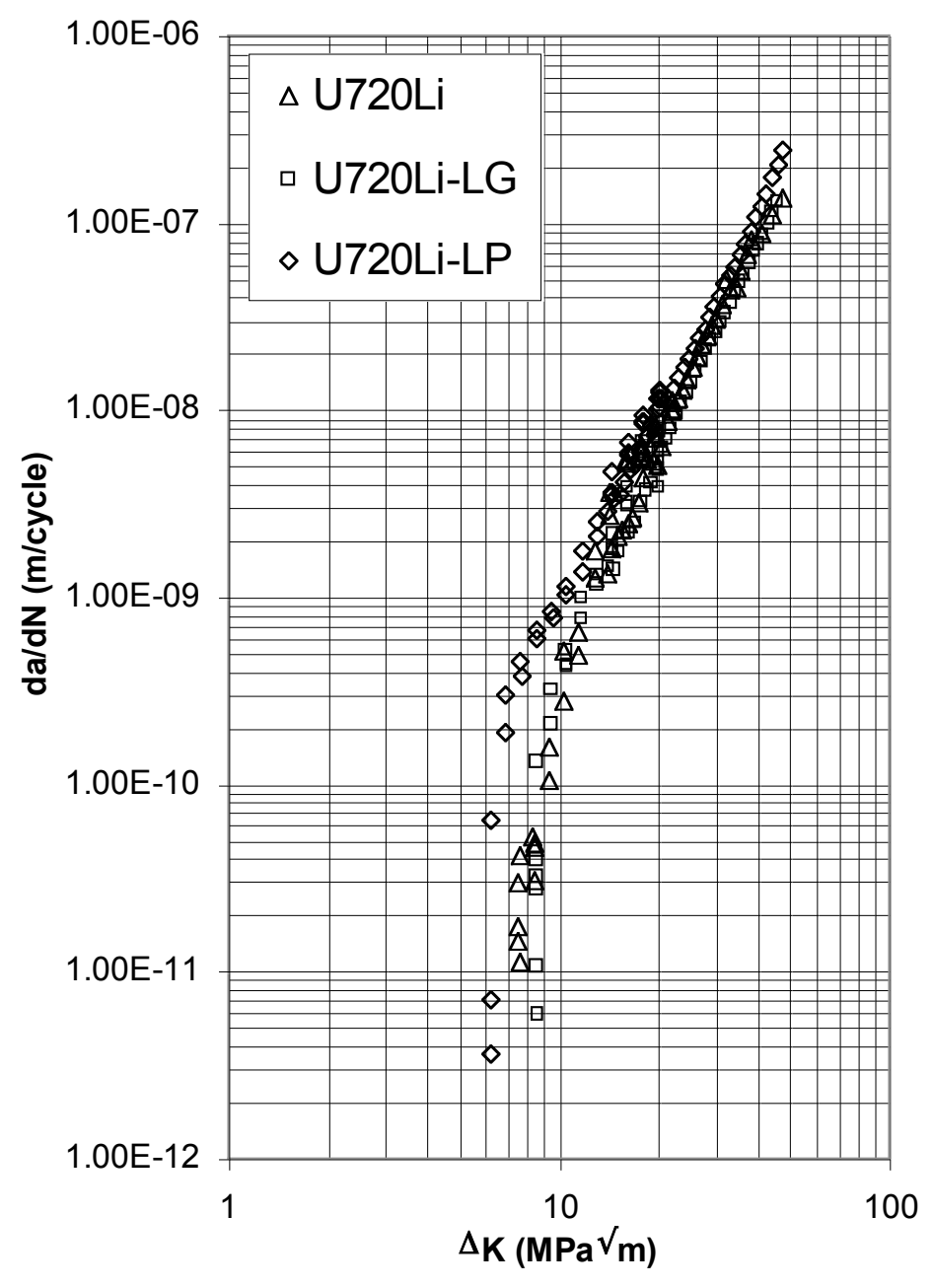

Figure 3: da/dN versus $\Delta \mathrm{K}$ behaviour of all 3 alloys at room temperature. 


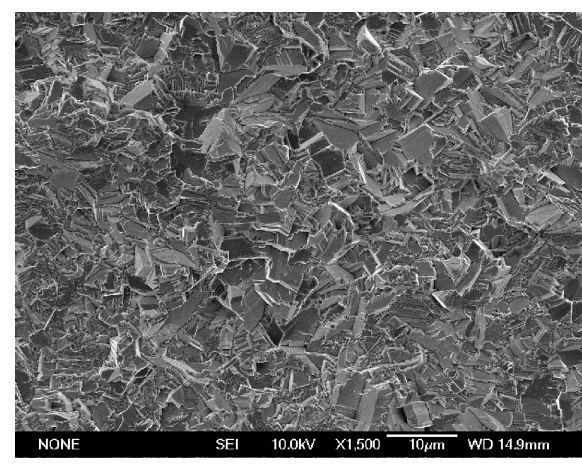

(a)

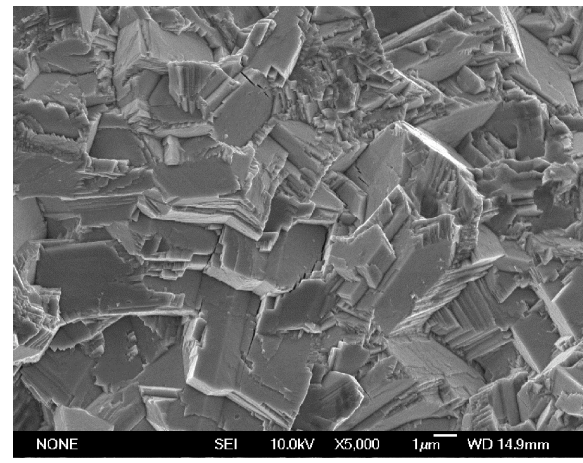

(c)

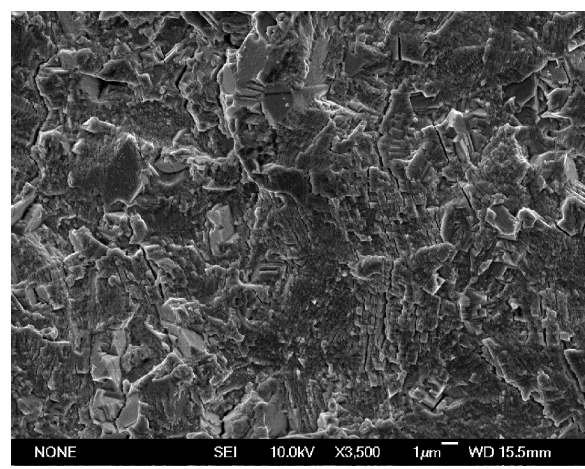

(e)

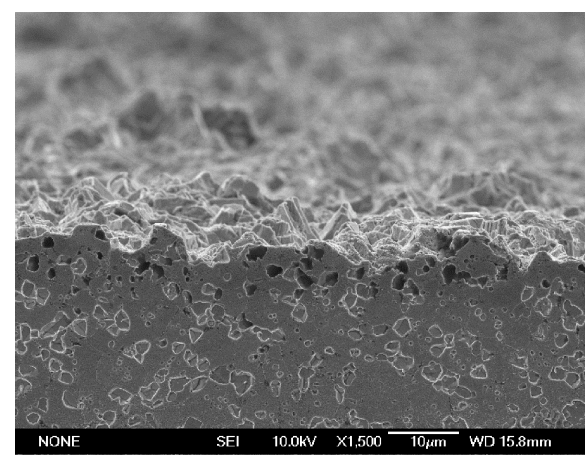

(b)

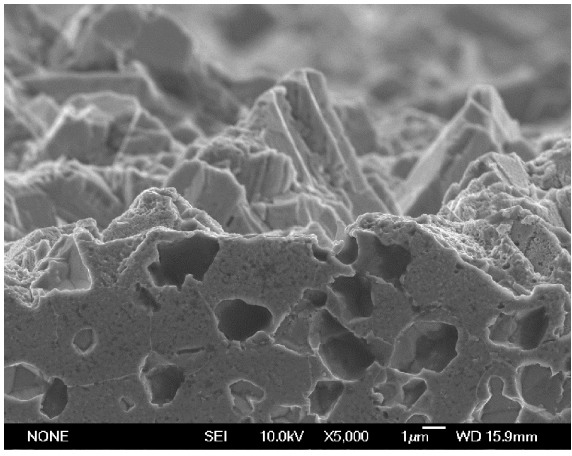

(d)

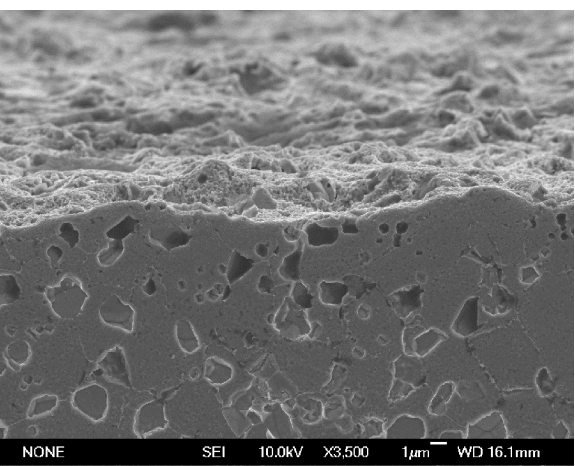

(f)

Figure 4: U720Li fractography: (a) Fracture surface near threshold at $\Delta \mathrm{K} \approx 7.5 \mathrm{MPa} \sqrt{\mathrm{m}}$ (b) Section of fracture surface, showing crack path through microstructure at $\Delta K \approx 7.5$ $\mathrm{MPa} \sqrt{\mathrm{m}}$ (c) Close-up of (a) (d) Close-up of (b) (e) Fracture surface at $\Delta \mathrm{K} \approx 25 \mathrm{MPa} \sqrt{\mathrm{m}}$ (f) Section of fracture surface, showing crack path through microstructure at $\Delta \mathrm{K} \approx 23$ $\mathrm{MPa} \sqrt{\mathrm{m}}$ 


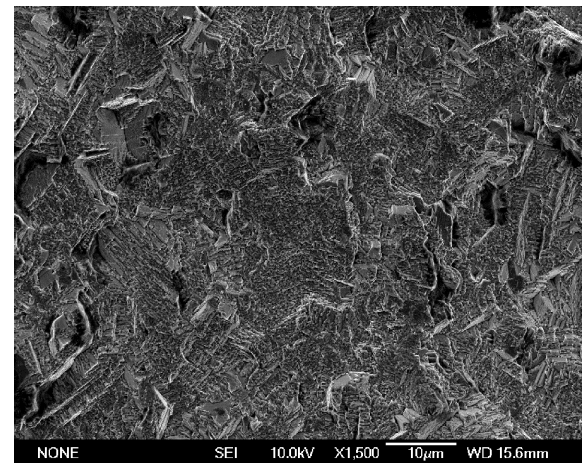

(a)

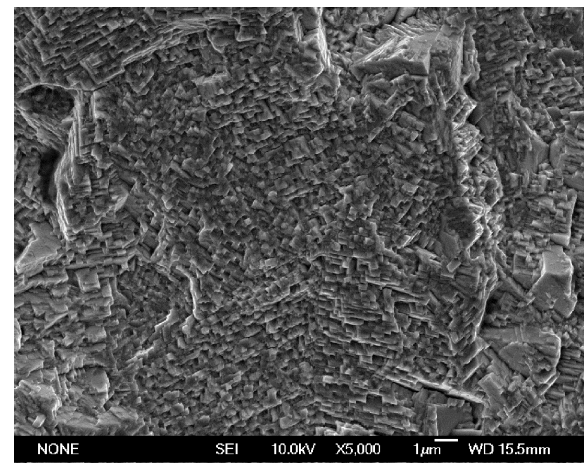

(c)

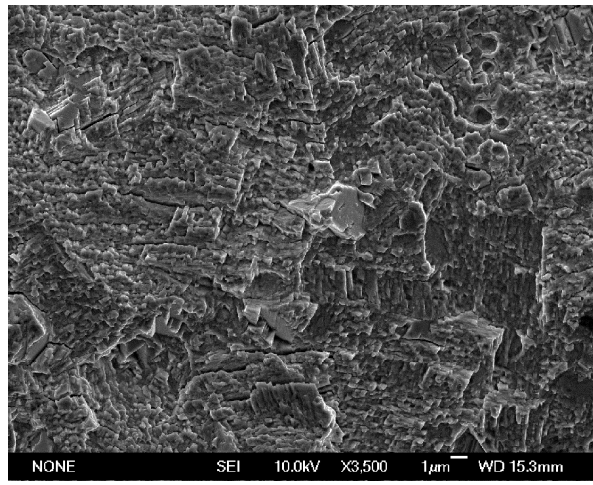

(e)

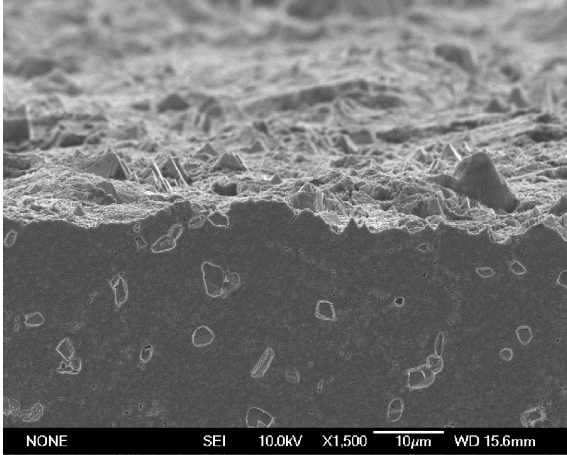

(b)

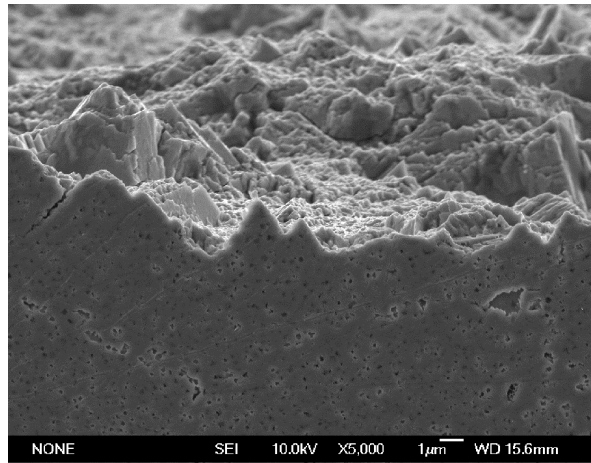

(d)

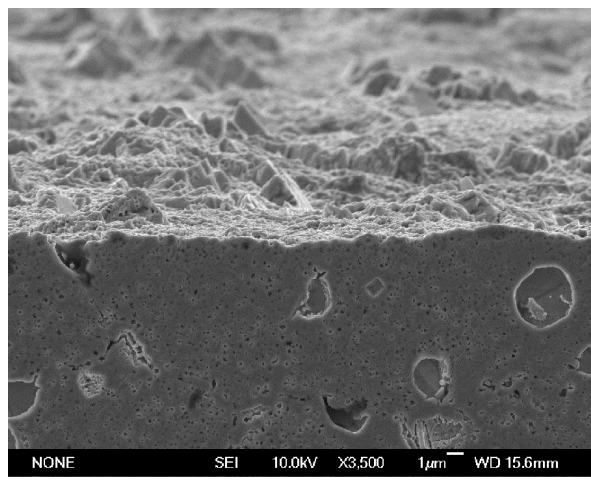

(f)

Figure 5: U720Li-LG fractography: (a) Fracture surface near threshold at $\Delta \mathrm{K} \approx 8.5$ $\mathrm{MPa} \sqrt{\mathrm{m}}$ (b) Section of fracture surface, showing crack path through microstructure at $\Delta \mathrm{K}$ $\approx 8.5 \mathrm{MPa} \sqrt{\mathrm{m}}$ (c) Close-up of (a) (d) Close-up of (b) (e) Fracture surface at $\Delta \mathrm{K} \approx 23$ $\mathrm{MPa} \sqrt{\mathrm{m}}$ (f) Section of fracture surface, showing crack path through microstructure at $\Delta \mathrm{K}$ $\approx 23 \mathrm{MPa} \sqrt{\mathrm{m}}$ 


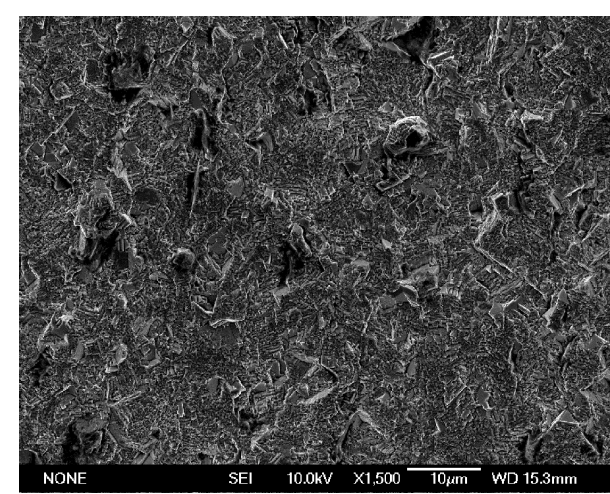

(a)

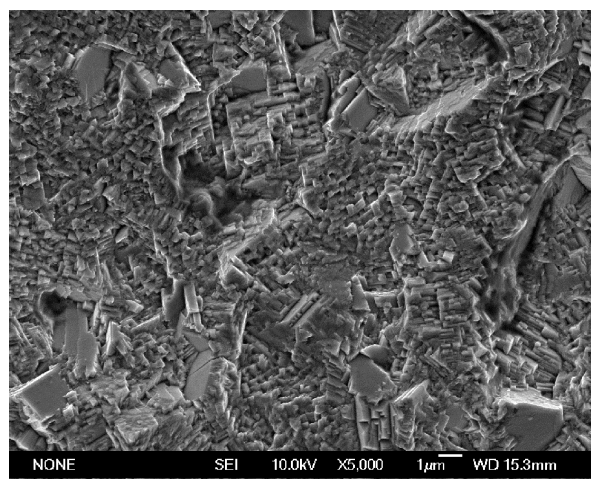

(c)

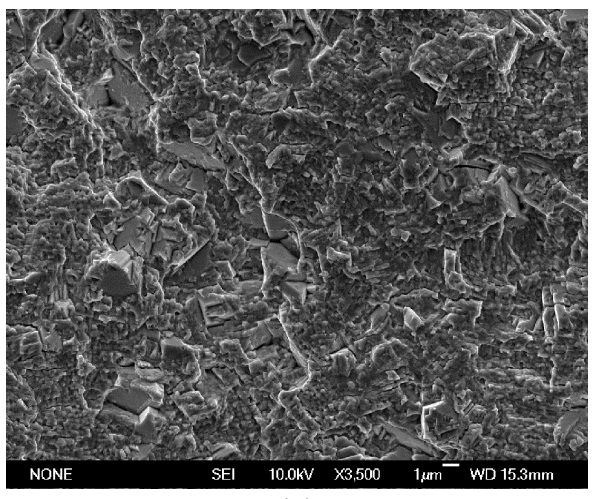

(e)

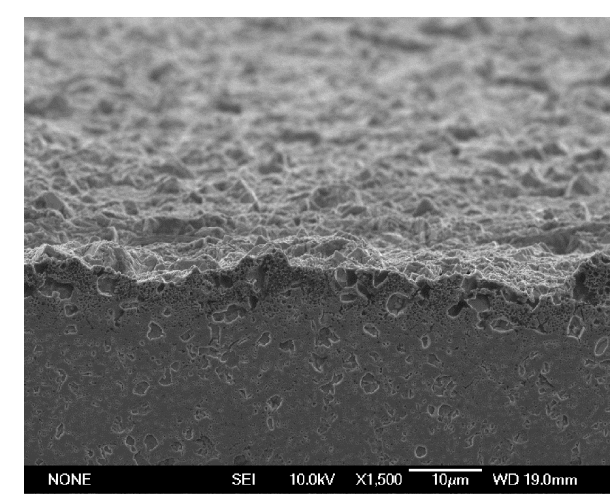

(b)

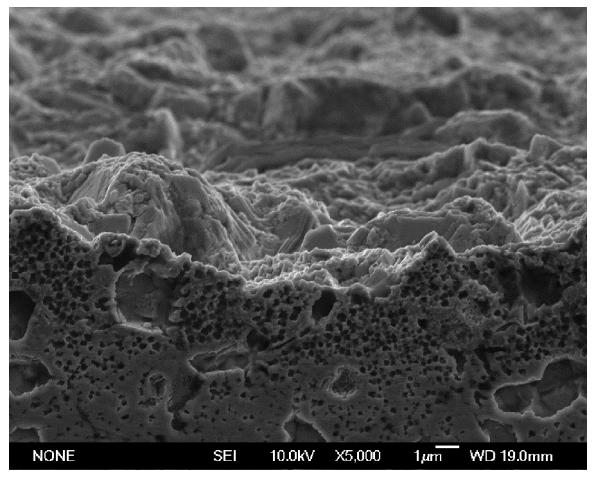

(d)

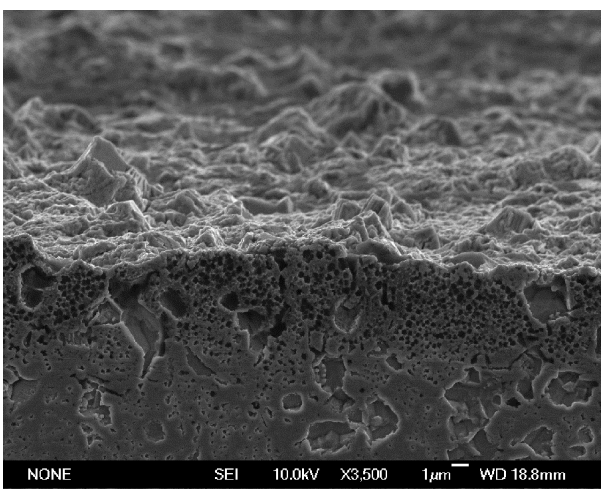

(f)

Figure 6: U720Li-LP fractography: (a) Fracture surface near threshold at $\Delta \mathrm{K} \approx 6 \mathrm{MPa} \sqrt{\mathrm{m}}$ (b) Section of fracture surface, showing crack path through microstructure at $\Delta \mathrm{K} \approx 6 \mathrm{MPa} \sqrt{\mathrm{m}}$ (c) Close-up of (a) (d) Close-up of (b) (e) Fracture surface at $\Delta \mathrm{K} \approx 24 \mathrm{MPa} \sqrt{\mathrm{m}}$ (f) Section of fracture surface, showing crack path through microstructure at $\Delta \mathrm{K} \approx 22 \mathrm{MPa} \sqrt{\mathrm{m}}$ 


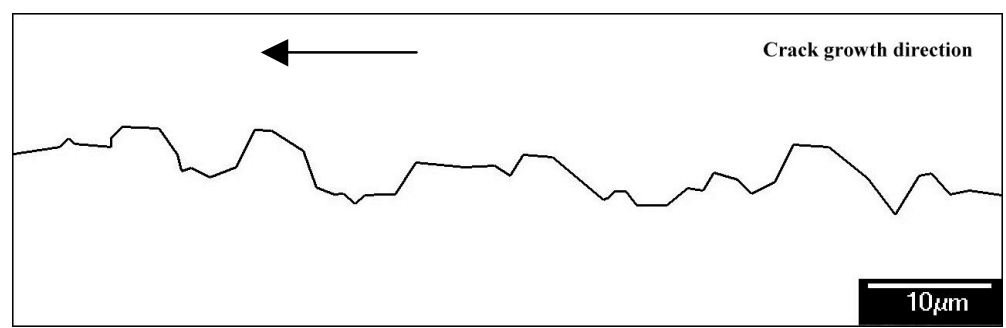

(a)

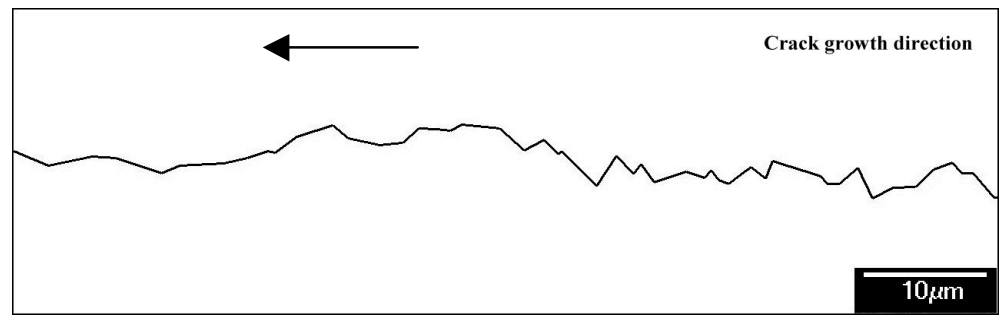

(b)

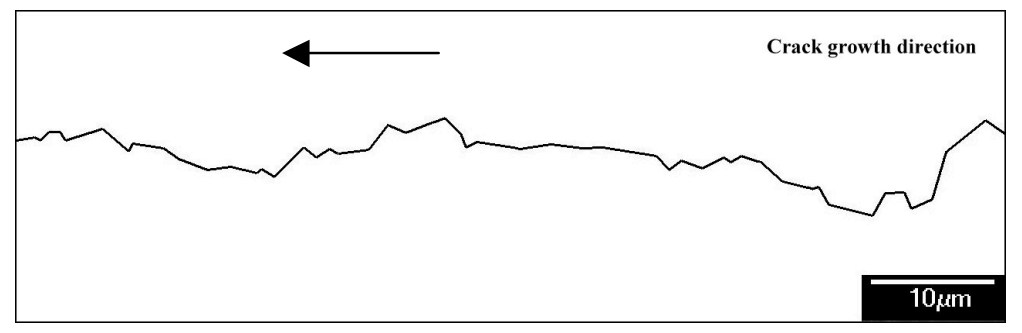

(c)

Figure 6: Crack profile at near-threshold $\Delta \mathrm{K}$ (a) U720Li (b) U720Li-LG (c) U720Li-LP 


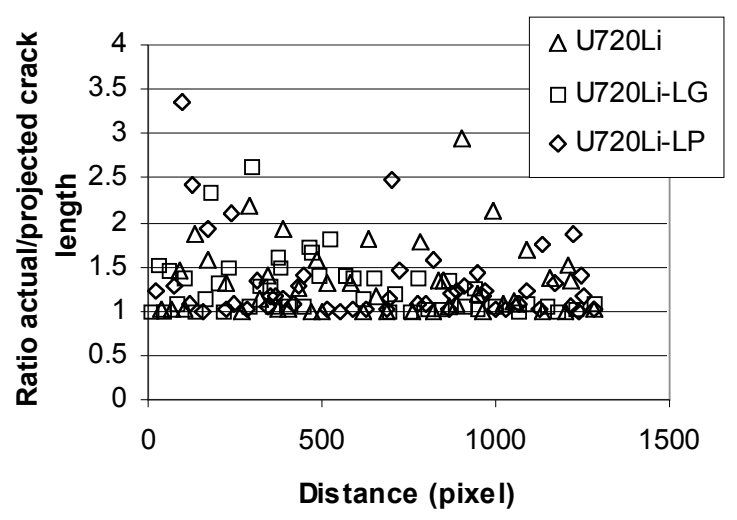

(a)

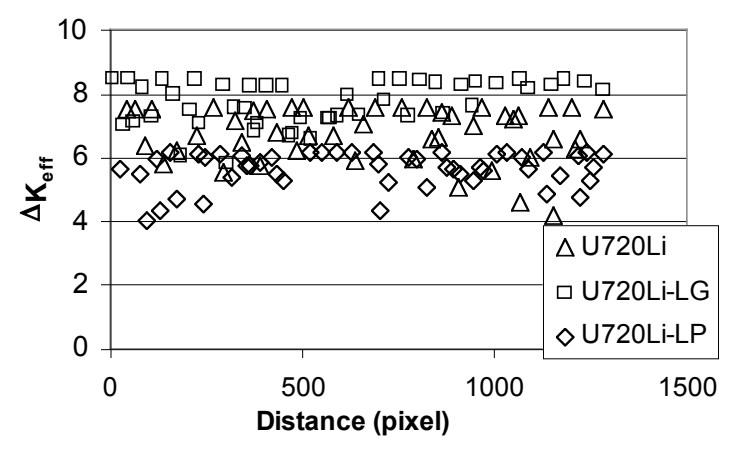

(c)

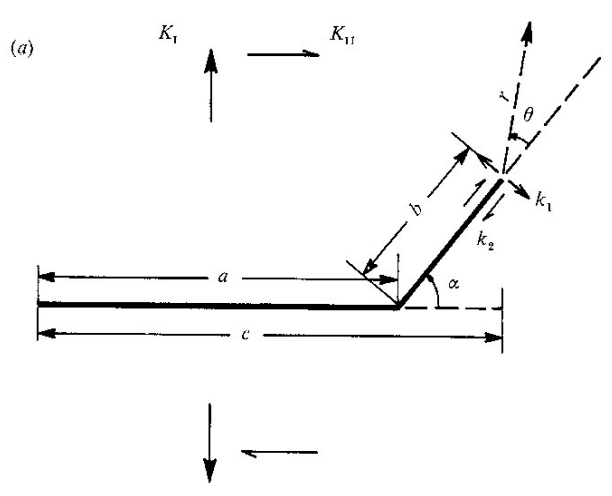

(b)

Figure 7: Crack deflection measurements: (a) Actual/projected crack length (b) Schematic representation of a deflected crack geometry (c) Local $\Delta \mathrm{K}_{\text {eff }}$ variation due to crack deflection. 


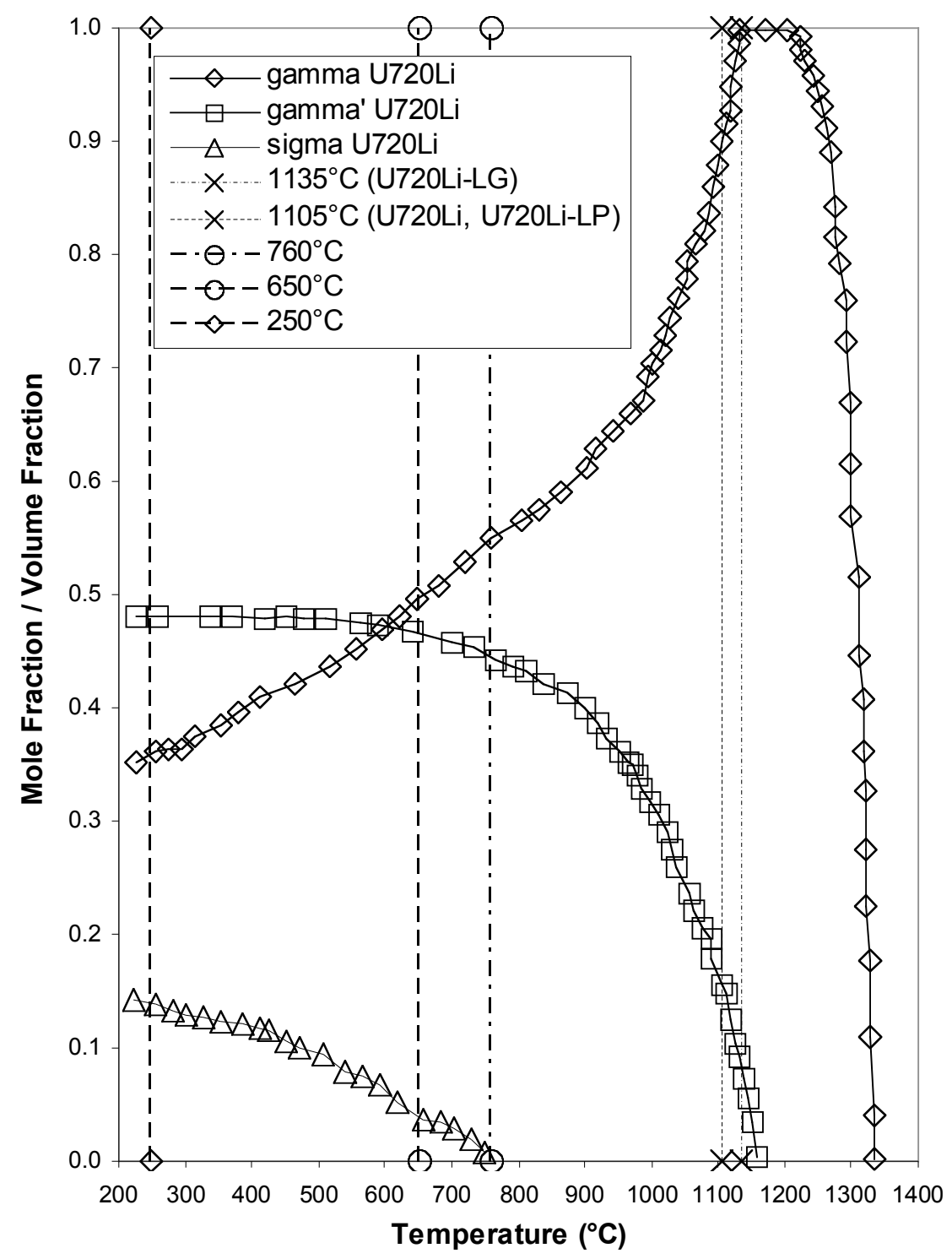

Figure 9: Thermo-calc prediction of phase distribution for U720Li (Cantab ref). 


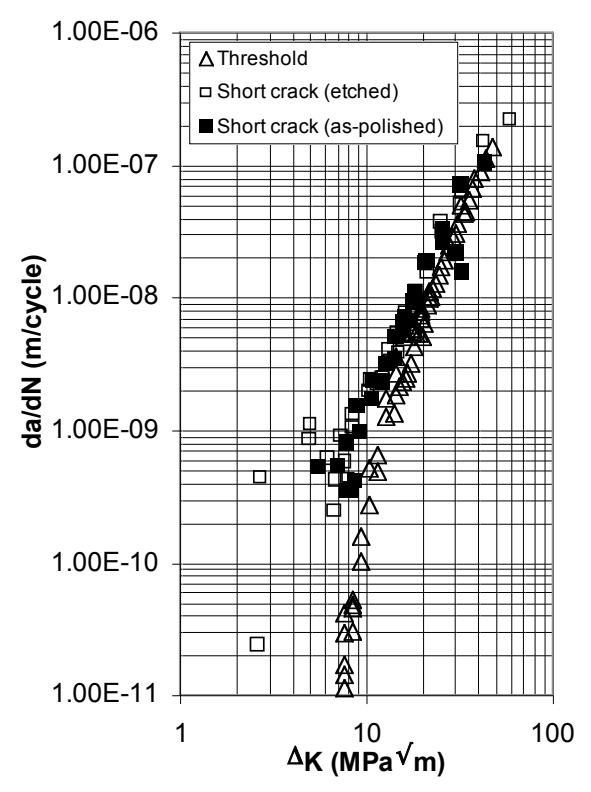

(a)

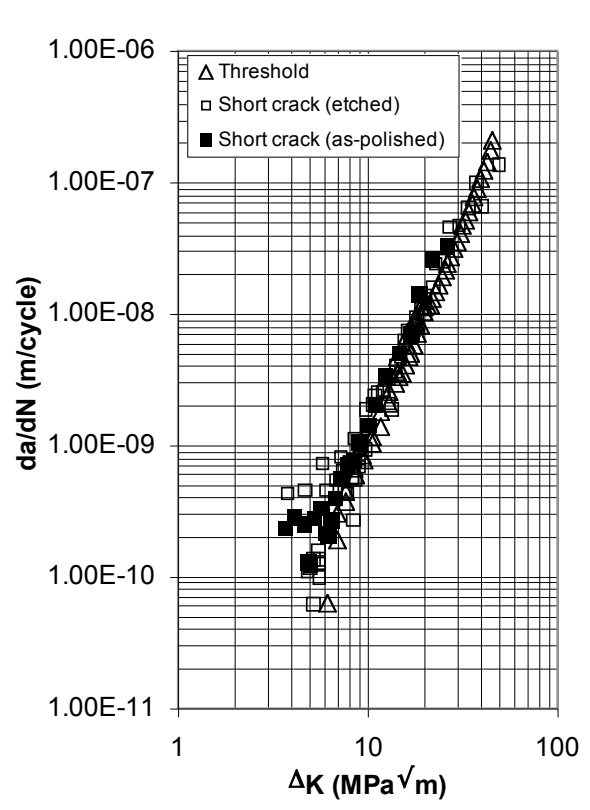

(c)

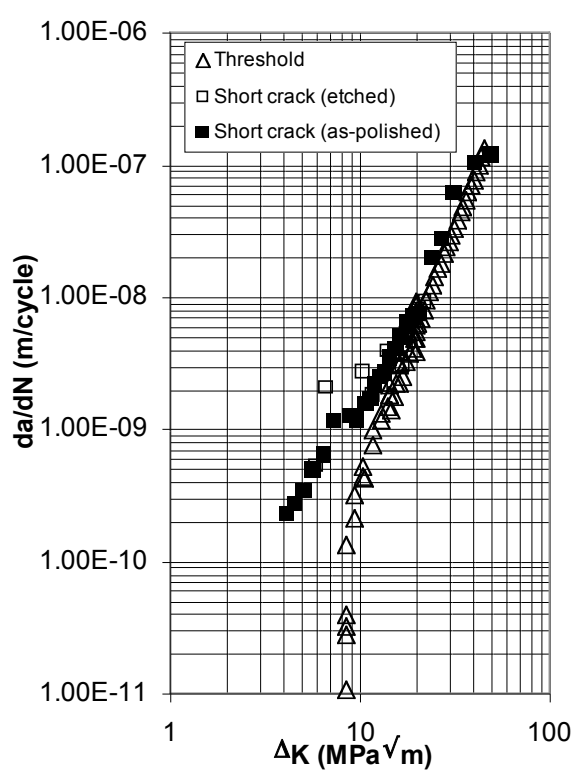

(b)

Figure 10: Room temperature long crack-short crack comparison (a) U720Li (b) U720LiLG (c) U720Li-LP 


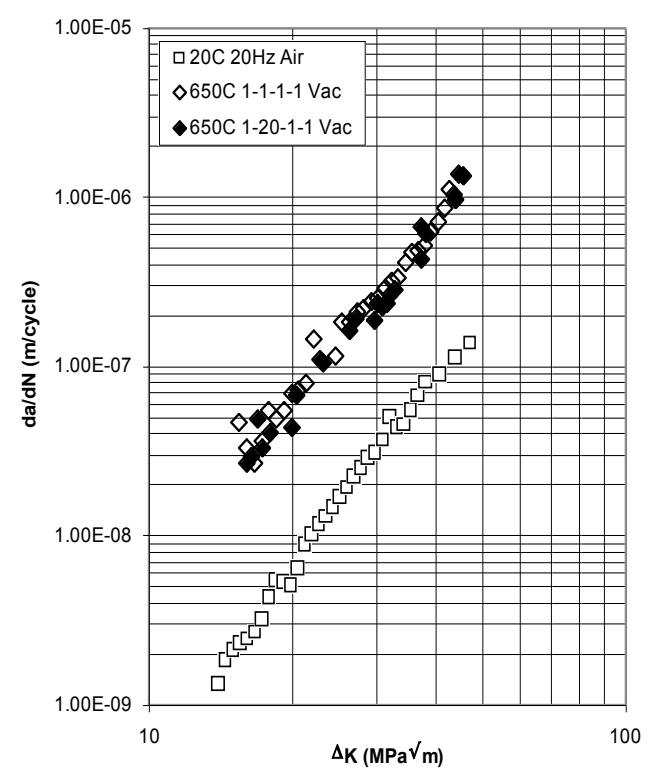

(a)

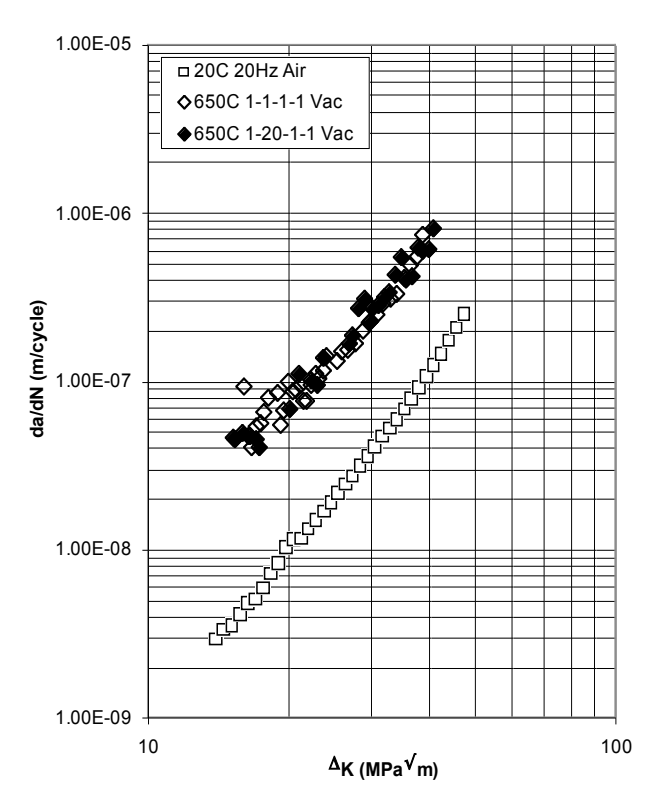

(c)

c)

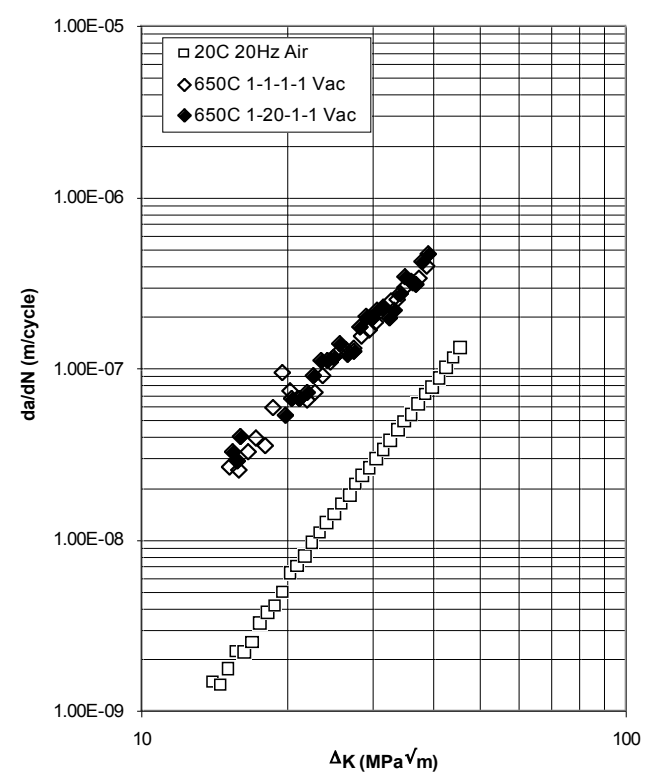

(b)

Figure 11: Room temperature vs. $650^{\circ} \mathrm{C}$ long crack growth comparison (a) U720Li (b) U720Li-LG (c) U720Li-LP 


\section{REFERENCES}

${ }^{1}$ Fournier, D. Pineau A. Metallurgical Transactions A, vol. 8A, pp. 1095-1105, 1977.

${ }^{2}$ Goto M., Knowles D.M. Engineering Fracture Mechanics, vol. 60, pp. 1-18, 1998.

${ }^{3}$ Miller K.J. Fatigue of Engineering Materials and Structures (UK), vol. 5, pp. 223-232, 1982.

${ }^{4}$ Wu Z., Sun X. Engineering Fracture Mechanics, vol. 59, pp. 353-359, 1998.

${ }^{5}$ Hicks M.A., Brown C.W. Fatigue 1984.

${ }^{6}$ Stephens R., Grabowski L., Hoeppner D.W. Short Fatigue Cracks, Sheffield, UK, Dec. 1990, Mechanical Engineering Publications Limited (UK), ISBN 0-85298-809-5, pp. 335-348, 1992.

${ }^{7}$ Yates J.R., Zhang W., Miller K.J. Fatigue and Fracture of Engineering Materials and Structures (UK), vol. 16, pp. 351-362, 1993.

${ }^{8}$ Lerch B.A., Jayaraman N., Antolovich S.D. Mater. Sci. Eng. 1984:66:151-166.

${ }^{9}$ Healy J.C., Grabowski L., Beevers C.J. Int. J. Fatigue 1991:13(2):133-138.

${ }^{10}$ Yates J.R., Zhang W., Miller K.J. Fatigue Fract. Engng Mater. Struct. 1993:16(3):351362.

${ }^{11}$ Smith R.A., Liu Y., Grabowski L. Fatigue Fract. Engng Mater. Struct. 1996:19(12):1505-1514.

${ }^{12}$ Mei Z., Krenn C.R., Morris J.W. Jr. Metall. Mater. Trans. A 1995:26A:2063-2073.

${ }^{13}$ Gayda J., Miner R.V. Int. J. Fatigue 1983:5(3):135-143.

${ }^{14}$ Davidson D.L., Chan K.S. Acta Metall. 1989:37(4):1089-1097. 
${ }^{15}$ Vecchio R.S., Hertzberg R.W. "A rationale for the 'apparent anomalous' growth behaviour of short fatigue cracks" Engineering Fracture Mechanics, vol. 22, pp. 1049$1060,1985$.

${ }^{16}$ Soniak F., Remy L. "Behaviour of long and short fatigue cracks in a powder metallurgy superalloy at room and at high temperature" Fatigue '87 Proceedings of 3rd Int. Conf. on Fatigue and Fatigue Thresholds, Charlottesville, Virginia, USA, 28 June-3 July 1987, Engineering Materials Advisory Services Ltd, pp. 351-360, 1987.

${ }^{17}$ Brown C.W., King J.E., Hicks M.A. "Effects of microstructure on long and short crack growth in nickel base superalloys" Metal Science, vol. 18, pp. 374-380, 1984.

${ }^{18}$ Zhang Y.H., Edwards L. "The development of plastic zones ahead of small fatigue cracks and their consequences for crack growth rate" Aluminium alloys, vol. 2, pp. 563$568,1992$.

${ }^{19}$ Reed P.A.S., King J.E. "Comparison of long and short crack growth in polycrystalline and single crystal forms of U720" Short Fatigue Cracks, Sheffield, UK, Dec. 1990, Mechanical Engineering Publications Limited (UK), ISBN 0-85298-809-5, pp. 153-168, 1992.

${ }^{20}$ H.T. Pang and P.A.S. Reed "Microstructure effects on high temperature fatigue crack initiation and short crack growth in turbine disc nickel-base superalloy Udimet 720Li" Materials Science and Engineering A (2007) 448, 67-79

${ }^{21}$ H.T. Pang and P.A.S. Reed "Microstructure variation effects on room temperature fatigue crack propagation and thresholds in Udimet 720Li Ni-base superalloy" in publication

${ }^{22}$ H.T. Pang and P.A.S. Reed, "Short Fatigue Crack Growth in Ni-Base Turbine Disc Alloys - The Effects of Microstructure and Operating Parameters.” Int. J. Fat., 25 (9-11) (2003) 1089-1099

${ }^{23}$ Hide N.J., Henderson M.B., Reed P.A.S. Proc. 9th International Symposium on Superalloys, Seven Springs, PA, USA (2000), Minerals, Metals and Materials Society/AIME, Superalloys 2000 (2000), pp. 495-503.

${ }^{24}$ Scott P.M. and Thorpe, T.W. "A critical review of crack tip stress intensity factors for semi-elliptic cracks" Fat. Eng, Mat. \& Struct. 4, 291-309 (1981) 
${ }^{25}$ T.L. Anderson, Fracture Mechanics - Fundamentals and Applications, CRC Press, 1994.

${ }^{26}$ Toh S.F., Rainforth W.M. "Fatigue of a nickel base superalloy with bimodal grain size" Materials Science and Technology, 12, 1007-1014, 1996

${ }^{27}$ Duva J.M. Daeubler M.A. Strake E.A. Jr, Luetjering G. "Large shearable particles lead to coarse slip in particle reinforced alloys" Acta Metallurgica, 36, 585-589, 1988 